\title{
ELEIÇÕES MUNICIPAIS DE 1996, COM ÊNFASE PARA O QUADRO DE SÃO PAULO
}

\author{
Monica Herman Salem Caggiano \\ Professora Associada do Departamento de Direito do Estado da FDUSP \\ Secretária dos Negócios Jurídicos da Prefeitura do Município de São Paulo \\ Coordenadora Adjunta do Curso de Especialização em Direito Empresarial \\ da Universidade Mackenzie
}

Resumo:

O presente trabalho tem por finalidade um exame, ainda que sucinto, do quadro eleitoral envolvendo o pleito de 1996 - eleições municipais destinadas à seleção de prefeitos e de vereadores.

O objetivo é o registro das questões de maior relevância que este momento eleitoral descortina, o seu tratamento legal, o debate emergente e as eventuais soluções.

Nessa trilha são abordados temas de vital notoriedade no âmbito do processo eleitoral, a exemplo da questão financeira, das possibilidades de marketing político, dos prazos de desincompatibilização e especial atenção ao dia de eleição com suas peculiaridades.

Enfim, a proposta é a de oferecer uma radiografia desse período eleitoral de 1996, resultante de um esforço científico de análise dos vários e diversificados escaninhos que esse alberga.

\begin{abstract}
:
This article explores the 1996 brazilian municipal elections, aiming to choose mayors and City Counsellors from january 1st on.

The purpose is to investigate the relevant and large issues that frame the 1996 electoral process, begining by revealing the complex and remarkably rich "regulating block", that means the general and particular laws, statutes and judicial decisions that regulate in the present year the electoral arena.

We shall discuss in this essay important and fashionable themes, just as the expense of running a campaign, regulations concerning advertising, levels of state support for political campaigns, time periods of residency and party affiliation required for candidature and a special analyse dedicated to the election day.

Finally, the focus shall be the mechanism of 1996 elections, with the task of analysing doctrine and the variety of structural and legal settings in which the electoral actors are supposed to work.
\end{abstract}

Unitermos: Eleições municipais; Zona Eleitoral. 
1.- Introdução

A complexidade e peculiar mutabilidade das regras e práticas eleitorais impõem, por mais uma vez, aos analistas o exame do quadro a envolver a consulta popular programada para o corrente ano de 1996, com vistas à escolha dos prefeitos municipais e dos vereadores a compor os Legislativos locais a partir de $1^{\circ}$ de janeiro de $1997 .^{1}$

É que, não-obstante a existência de um respeitável complexo normativo de regência desse sofisticado campo, o legislador ordinário tem entendido indispensável a edição de leis específicas para o disciplinamento particular de cada uma das consultas. Assim, já consolidada a tradição de normas especiais de regulação dos pleitos, talvez em razão do célere avanço das técnicas utilizadas nessa esfera de atuação e das transformações a atingir a própria sociedade, com reflexos imediatos quanto a suas demandas, o espectro eleitoral descortina, a cada pleito, uma série de inovações, impondo aos analistas renovado esforço na reconstrução dos vários e diversificados escaninhos que compõem o processo eleitoral.

Daí a exigência, diante da pretensão de dissecar o processo eleitoral de 1996, para a seleção de prefeitos e vereadores, de especial registro em relação ao bloco legal a discipliná-lo, a par da análise de questões que, costumeiramente, conferem ao tema um aspecto exótico e altamente controvertido.

\section{2.- Do bloco legal}

No âmbito do bloco legal a incidir sobre o processo seletivo de 1996, emerge em posição sobranceira a Lei n. 9.100, de 29 de setembro de 1995, texto que estabelece as regras para a realização desse pleito, principiando sua ação regulamentadora com a fixação da data da consulta (03.10.96) e, nas hipóteses de ocorrência do segundo turno 15.11.96. O diploma vai além: fixa prazo de carência quanto aos requisitos domicílio eleitoral e filiação partidária (esse último, aliás, em flagrante contradição com a regra básica do art. 18 da Lei dos Partidos Políticos Lei n. 9.096/95, paradoxalmente editada dez dias antes), autoriza coligações e normatiza sua concretização e funcionamento, dispõe sobre o registro das candidaturas, dos meios e fórmulas de fiscalização aplicáveis, da arrecadação e da

1. As eleições municipais de 1996 envolvem a disputa de oitenta mil vagas para prefeito e vereador, por cerca de oitocentos mil a um milhão de candidatos, em todo o Brasil. 
aplicação dos recursos financeiros, da propaganda e faz estrear, a nível de exigência legal, a previsão de reserva de cota especial, dedicada à candidatura feminina (20\% das vagas de cada partido ou coligação), donde sua rotulação de Lei das Cotas.

Aliás, relevante se nos afigura transcrever a postura protecionista, adotada pelo E. Tribunal Superior Eleitoral sobre a cota feminina, ao responder a Consulta n. 157, do Distrito Federal, in verbis:

"Ementa Candidaturas Femininas Se não se
preencherem os $20 \%$ das vagas destinadas às
candidaturas femininas, a chapa poderá ser registrada,
ainda que incompleto aquele percentual de mulheres. $O$
que não se admite conforme entendimento firmado por
esta Corte, é que a diferença seja preenchida por
candidatos-homens". (D.J. 10.07.96)

É de se notar, porém, a par da relevante estréia da cota feminina, que, diante de um exame perfunctório, o documento oferece ao leitor a errônea impressão de exaurir o disciplinamento do quadro eleitoral a emoldurar os pleitos municipais de 1996, conquanto, em verdade, outros textos legais continuam irradiando seus comandos sobre as eleições deste ano.

Parece-nos salutar, nessa esteira, apontar o próprio Código Eleitoral, Lei n. 4.737, de 15 de julho de 1965, (ou o que restou de seus dispositivos), com especial ênfase ao capítulo dos crimes eleitorais e ao macroprincípio insculpido no seu art. 237, voltado a robustecer a garantia de lisura do processo e a vedar ingerências emanadas do poder econômico, inclusive da máquina estatal a deteriorar o resultado do pleito.

No elenco de preceitos vedativos, resultantes de desdobramentos do já assinalado princípio consagrado pelo art. 237 do diploma eleitoral, merece registro a denominada Lei Etelvino Lins - Lei n. 6.091, de 15 de agosto de 1974 originariamente direcionada à regulação do transporte de eleitores e que, hoje, mantém destacada posição em função do disposto no seu art. 13, que inaugurou regra proibitiva quanto ao ingresso, dispensa e movimentação nos quadros de pessoal do serviço público estadual e municipal.

Referida norma alimentou acirrada polêmica quanto a sua vigência e aplicação por ocasião do pleito de 1990 quando, de forma excepcional, o legislador se mostrou silente no tocante à regulação das eleições. Na ausência de regra 
específica, o E. Tribunal Superior Eleitoral acabou por lhe acoplar o caráter permanente (Resolução n. 16.437, de 03 de maio de 1990), posição reforçada pelo C. Supremo Tribunal Federal que declarou também sua constitucionalidade (RE 92.728-BA). O preceito, aliás, tem sua incidência assegurada no que toca às eleições de 1996, até porque a norma projetada pelo Legislativo, quando da elaboração da atual Lei n. 9.100/95 - (art. 77), foi objeto de veto presidencial. Em especial, no Município de São Paulo, a regra vem servir de respaldo e fundamento à Ordem Interna n. 11/96 do prefeito, que orienta acerca dos atos administrativos que poderão ser praticados no período eleitoral, em relação a servidores públicos.

O campo das inelegibilidades, de outra parte, vem subordinado à Lei Complementar n. 64, de 18 de maio de 1990, cujos dispositivos de maior interesse para os pleitos municipais podem ser visualizados no quadro infratranscrito:

Prazos de desincompatibilização - Eleições municipais/1996

\begin{tabular}{|c|c|c|}
\hline Cargo exercido & Prefeito & Vereador \\
\hline Administrador Regional & exoneração/4 meses & exoneração/6 meses \\
\hline Procurador Geral & $"$ & $"$ \\
\hline Diretor de Dep. & $"$ & $"$ \\
\hline $\begin{array}{l}\text { Chefe de Assessoria e } \\
\text { Supervisor }\end{array}$ & $"$ & $"$ \\
\hline Coordenador e Supervisor & $"$ & $"$ \\
\hline Chefe de Gabinete & $"$ & $"$ \\
\hline $\begin{array}{l}\text { Os servidores que tenham } \\
\text { interesse direto na arrecada- } \\
\text { ção, lançamento, fiscalização } \\
\text { de tributo ou para aplicar } \\
\text { multas }\end{array}$ & $"$ & $"$ \\
\hline Servidor público municipal & $\begin{array}{l}\text { afastamento/ } 3 \text { meses, } \\
\text { assegurada percepção } \\
\text { integral dos vencimen- } \\
\text { tos (Res.TSE- } \\
\text { 18.019/92.) }\end{array}$ & $\begin{array}{l}\text { afastamento/ } 3 \text { meses, } \\
\text { assegurada percepção } \\
\text { integral dos vencimen- } \\
\text { tos (Res.TSE- } \\
18.019 / 92 \text { ) }\end{array}$ \\
\hline
\end{tabular}

Relevante é notar a hipótese de desincompatibilização dos servidores públicos da Administração Direta e Indireta, que sofreu alteração de tratamento não apenas por parte do legislador, como também, por força da jurisprudência construtiva emanada da Justiça Eleitoral. Assim, num primeiro passo, cumpre frisar 
que a modelagem adotada pela Lei Complementar n. 64/90 ofereceu contornos diferentes à figura do afastamento do servidor público para a promoção da respectiva campanha (art. $1^{\circ}, \mathrm{II}$, "l"). Até aí, esse afastamento recebia o tratamento de favor legal, mera liberalidade que o servidor poderia usar ou não. Um benefício assegurado a cada nova consulta eleitoral pelo respectivo diploma regulamentador.

$\mathrm{Na}$ sua nova roupagem, contudo, foi erigido à hipótese de inelegibilidade, obrigando o servidor a se afastar de suas funções, assegurados os vencimentos, por um período fixado em razão da data do pleito e não mais do registro da respectiva candidatura. ${ }^{2} \mathrm{E}$ mais, nesse particular domínio, o próprio prazo de afastamento acabou sendo fixado pelo exercício da função normativa da Justiça Eleitoral, que estendeu aos pleitos municipais o período de 3 (três) meses preconizado pelo já referido art. $1^{\circ}$, II, "1". enquanto que, por força do disposto nos incisos IV e VII desse mesmo preceito, os prazos seriam de quatro e seis meses, dependendo da candidatura visar o cargo de prefeito ou de vereador. $\mathrm{E}$ mais ainda, nulificou o E. Tribunal Superior Eleitoral a viabilidade de afastamento quanto às candidaturas a cargos não-pertinentes ao Município em que o servidor exercesse suas funções. Memorável, pois, a decisão consagrada por intermédio da Resolução n. 18.019-DOU 07.04.92, in verbis:

"I, a: Aplica-se às eleições municipais a inelegibilidade da alínea $l$, do art. $1^{\circ}$, II, da Lei Complementar n. 64/90, desde que vinculado o servidor candidato a repartição, fundação pública ou empresa que opere no território do município.

I, b: Para excluir a inelegibilidade de que cuida o item I, a, supra, deve o candidato às próximas eleições municipais afastar-se do cargo, emprego ou função até 2 de julho ...

I, c: O servidor afastado para o fim do item 2, supra, tem direito à remuneração integral por todo o tempo de afastamento exigido."

2. No Município de São Paulo, a questão foi objeto de regulamentação especial Portaria $n$. 81/SMA-G.96 da Secretaria Municipal da Administração, que, atendido o quadro normativo eleitoral, estabeleceu os trâmites processuais e condições de deferimento dos pedidos de afastamento formulados pelos servidores/candidatos. 
Interessante assinalar, também, as razões que conduziram a mais alta Corte Eleitoral a tal interpretação, igualando, em relação a todos os servidores públicos, independentemente do pleito a que venham a concorrer, o período necessário para fins de desincompatibilização: três meses. Tal solução, resta anotado no mencionado decisório, "impede conseqüências catastróficas, dificilmente conciliáveis com o princípio constitucional da moralidade, quando transposta para o prisma de seus reflexos sobre a Administração Pública"

Integrando o rol da legislação aplicável ao quadro eleitoral de 1996, não há como deixar de assinalar a nova lei dos partidos políticos, Lei n. 9.096, de 19 de setembro de 1995, já em plena operabilidade, em especial no que toca à previsão de veiculação publicitária pelo sistema de curtas inserções, com a participação inclusive dos candidatos, mecanismo já absorvido pelos partidos de maior força político-eleitoral e com o qual a sintonia foi instantânea.

De fato, o diploma contemplou as agremiações partidárias de forma generosa com o acesso gratuito ao rádio e à televisão, preconizando, a par da possibilidade de divulgação, por semestre, de um programa em cadeia nacional e um em cadeia estadual, com a duração de 20 minutos, a utilização de inserções nesses veículos de comunicação, de trinta segundos a um minuto, perfazendo um total de oitenta minutos semestrais, quarenta em emissoras nacionais e outros quarenta nas estaduais (art. 49). No que toca ao programa semestral, o texto disciplinou a matéria para o período compreendido entre a sua edição e o início da próxima legislatura, seguindo modelo mais econômico (art. 56, II e III). Não ofereceu, porém, tratamento diferenciado à nova técnica publicitária por via de inserções. E essas inundaram as telas no primeiro semestre do corrente ano, sendo acopladas a um marketing préeleitoral das candidaturas já definidas pelos respectivos partidos.

Questionada a utilização da propaganda partidária, por spots, para fins eleitorais e antes mesmo de qualquer definição, por via do processo de registro das candidaturas, a Justiça Eleitoral (Representação do Ministério Público Eleitoral contra inserções realizadas pelo PPB decisão da $1^{\text {a }}$ Zona Eleitoral da Capital de São Paulo, datada de 11 de maio de 1996) concluiu incorrer qualquer vedação legal no tocante à transmissão de programas partidários que tenham como protagonista pré-candidato, frisando que "pelo fato de aparecer o pré-candidato para difundir $o$ programa é, sem dúvida antiético, mas não ilegal".

Alinhando-se ao quadro produzido pelo legislador, não há como ignorar os atos reguladores emanados da Justiça Eleitoral com base na sua 
competência normativa e formalizados por via de Instruções. Nessa esteira, a comandar os pleitos eletivos de 1996 ,

o Calendário Eleitoral (Resolução n. 19.382, DJU 22.11.95 p. 40.009), e as Instruções de n. 2 (Escolha e Registro dos Candidatos), 4 (Prestação de Contas das Campanhas Eleitorais), 6 (Recibo Eleitoral), 11 (Propaganda), 12 (Pesquisas Eleitorais), 13 (Atos Preparatórios, Cédula Eleitoral, Recepção dos Votos e Garantias Eleitorais), 14 (Atos Preparatórios, Cédula Eleitoral, Recepção de Votos e Garantias Eleitorais nas seções em que for utilizado o sistema eletrônico de votação), 15 (Formulários para as eleições), 16 (Apuração das eleições nas seções, aonde não for utilizado o sistema eletrônico de votação), e 17 (Apuração das eleições nas seções, aonde for utilizado o sistema eletrônico de votação), todas publicadas no DJU de 25.04 .96 pp. 12.993 e seguintes.

\section{3.- Dos partidos políticos}

Nos termos do modelo eleitoral agasalhado pelo texto da Lei Maior (art. $14, \S 3^{\circ}, \mathrm{V}$ ), na paisagem doméstica não há lugar para candidaturas independentes. ${ }^{3}$ As candidaturas são vinculadas a partidos políticos, embora não mais perdure a regra da plena e exclusiva responsabilidade das agremiações políticopartidárias no concernente à realização das campanhas eleitorais. Impõe-se, assim, um exame ainda que sucinto - do quadro partidário, dos partidos que, isoladamente ou por intermédio da figura da coligação, engajaram-se no processo eleitoral e da responsabilidade do partido no tocante ao desenvolvimento da campanha e às ações que envolvem a disputa dos votos.

O panorama brasileiro oferece-se propício à proliferação das formações político-partidárias, ensejando uma considerável pulverização, um turismo interpartidário, de contornos bastante acentuados a nível parlamentar, e o surgimento em cena política dos denominados partidos nanicos. $\mathrm{O}$ quadro coloca o analista, de imediato, diante de uma realidade de 32 partidos políticos 26 com

3. Sobre o tema, aliás, oportuna a observação do Professor Cláudio Lembo, no sentido de que " $o$ virtual monopólio conferido aos partidos políticos na indicação, apresentação e divulgação de candidatos, por toda parte, concede-lhes uma relevância especial no quadro das instituições políticas, a ponto de, hoje, estar em curso uma tendência à 'constitucionalização' destas associações". Participação Política e Assistência Simples, São Paulo, Forense Universitária, 1991. 
registro definitivo, 4 com registro provisório e 2 com requerimento em tramitação, solicitando capacitação jurídica.

\section{QUADRO PARTIDÁRIO}

\begin{tabular}{|c|c|c|}
\hline Partidos com registro definitivo & \begin{tabular}{|l} 
Partidos com registro \\
provisório
\end{tabular} & $\begin{array}{l}\text { Partidos com soli- } \\
\text { citação de capa- } \\
\text { citação iurídica } \\
\end{array}$ \\
\hline $\begin{array}{l}\text { PCdoB - Partido Comunista do } \\
\text { Brasil }\end{array}$ & $\begin{array}{l}\text { PAN Partido dos } \\
\text { Aposentados da } \\
\text { Nação }\end{array}$ & \begin{tabular}{|l} 
PFB - Partido \\
Feminista \\
Brasileiro
\end{tabular} \\
\hline $\begin{array}{l}\text { PCB Partido Comunista } \\
\text { Brasileiro }\end{array}$ & $\begin{array}{l}\text { PCO Partido da } \\
\text { Causa Operária }\end{array}$ & $\begin{array}{l}\text { PJP Partido de } \\
\text { Justiça Popular }\end{array}$ \\
\hline $\begin{array}{l}\text { PDT Partido Democrático } \\
\text { Trabalhista }\end{array}$ & $\begin{array}{l}\text { PSDC - Partido Social } \\
\text { Democrata Cristão } \\
\text { (ex-PDC) }\end{array}$ & \\
\hline PFL - Partido da Frente Liberal & $\begin{array}{l}\text { PSN Partido } \\
\text { Solidarista Nacional } \\
\end{array}$ & \\
\hline$P L-$ Partido Liberal & & \\
\hline $\begin{array}{l}\text { PMDB - Partido do Mov. } \\
\text { Dem.Brasileiro } \\
\end{array}$ & & \\
\hline $\begin{array}{l}\text { PMN - Partido da Mobilização } \\
\text { Nacional }\end{array}$ & & \\
\hline $\begin{array}{l}P P B \text { - Partido Progressista } \\
\text { Brasileiro(fusão entre PPR/PP) }\end{array}$ & & \\
\hline PPS - Partido Popular Socialista & & \\
\hline $\begin{array}{l}\text { PRN - Partido da Reconstrução } \\
\text { Nacional }\end{array}$ & & \\
\hline $\begin{array}{l}\text { PRONA Partido de Reedifição da } \\
\text { Ordem Nacional } \\
\end{array}$ & & \\
\hline $\begin{array}{l}\text { PRP Partido Republicano } \\
\text { Progressista }\end{array}$ & & \\
\hline \begin{tabular}{|ll}
$P S B$ & Partido Socialista Brasileiro \\
\end{tabular} & & \\
\hline $\begin{array}{|ll|}\text { PSC } & \text { Partido Social Cristão } \\
\end{array}$ & & \\
\hline PSD Partido Social Democrático & & \\
\hline $\begin{array}{l}\text { PSDB Partido da Social } \\
\text { Democracia Brasileira } \\
\end{array}$ & & \\
\hline PT Partido dos Trabalhadores & & \\
\hline $\begin{array}{l}\text { PTB Partido Trabalhista } \\
\text { Brasileiro }\end{array}$ & & \\
\hline $\begin{array}{l}\text { PTdo B Partido Trabalhista do } \\
\text { Brasil }\end{array}$ & & \\
\hline
\end{tabular}




\begin{tabular}{|l|l|l|}
\hline PV Partido Verde & & \\
\hline PSTU Partido Socialista dos & & \\
Trabalhadores Unificado & & \\
\hline PRTB Partido Renovador & & \\
Trabalhista Brasileiro & & \\
\hline PTN Partido Trabalhista & & \\
Nacional & & \\
\hline PGT - Partido Geral dos & & \\
Trabalhadores & \\
\hline PST Partido Social Trabalhista & & \\
\hline PSL - Partido Social Liberal & & \\
\hline
\end{tabular}

Desse invejável elenco de opções partidárias, poucos aqueles que efetivamente contam com adequado nível de representatividade. Como de maior expressão, continuam com o seu domínio o PMDB (107 deputados eleitos no último pleito de 1994, com uma bancada total de 129, incluindo os senadores), o PFL (90 deputados eleitos/94-bancada de 107 congressistas, incluindo os senadores), o PSDB (63 deputados eleitos/94-bancada de 73 congressistas, incluindo os senadores), o PPB (decorrente da fusão do PPR e do PP que elegeram em 1994, em conjunto, 99 deputados), o PT (49 deputados bancada de 54 congressistas, incluindo os senadores). E, dentre os de menor densidade eleitoral, podemos anotar casos como o do PL (14 congressista), PC do B (10 congressistas), PMN (4 congressistas), PSC (3 congressistas), PPS (3 congressistas), PRP (1 congressista), PRN (1 congressista) e PV (1 congressista).

As agremiações de menor expressividade eleitoral ingressam na disputa basicamente por via de coligações (para os pleitos municipais de 1996 autorizadas desde que pertinentes à eleição majoritária e proporcional ou apenas à majoritária - art. $6^{\circ}$ ), comumente visando a ampliação do tempo de antena ${ }^{4}$ dos mais poderosos, conquistando, em contrapartida, recursos de marketing e espaço mais promissor para os seus próprios candidatos. Por vezes, porém, sua participação tem por escopo mero ato de presença eleitoral, presença que, quando não produz efeitos nocivos sobre a campanha, por privilegiar, a partir da sombra, candidato de maior

4. A questão aqui tratada diz respeito ao tempo de cada partido no horário gratuito de propaganda eleitoral no rádio e na televisão. A partilha, nos moldes preconizados pelo legislador, sofre forte influência da representação de que dispõe cada agremiação junto à Câmara dos Deputados. As coligações, notadamente para os pleitos majoritários, sofrem o reflexo da necessidade de ampliação desse tempo de antena, poderoso veículo de marketing político-eleitoral. (Lei n. 9.100/95- art. 56 e ss.) 
potencial, é salutar para o robustecimento da participação política e ampliação das possibilidades de exercício da cidadania.

As eleições municipais de 1996 já têm um quadro definido nesse sentido. Assim, em São Paulo, concorrendo ao pleito de 3 de outubro há o registro:

\begin{tabular}{|l|l|} 
Partidos Expressivos/Coligações & Partidos Nanicos \\
\hline $\begin{array}{l}\text { PSDB /coligação SP com PPS, PV e PSL/candidato } \\
\text { José Serra/ 15min.27seg. }\end{array}$ & $\begin{array}{l}\text { PSC/candidato Pedro de } \\
\text { Camilo Neto }\end{array}$ \\
\hline $\begin{array}{l}\text { PMDB/ coligação Viver São Paulo, com PSDC/can- } \\
\text { didato João Leiva ou José A. Pinotti (disputando a } \\
\text { candidatura perante a Justiça Eleitoral/17min.54seg.) }\end{array}$ & $\begin{array}{l}\text { PRTB/candidato José } \\
\text { Levy Fidelis / 1 min.48 } \\
\text { segs. }\end{array}$ \\
\hline $\begin{array}{l}\text { PPB/Coligação Não Deixe São Paulo Parar com PFL/ } \\
\text { candidato Celso Pitta/ 29 min.9seg. }\end{array}$ & $\begin{array}{l}\text { PSTU/candidato Valério } \\
\text { Arcary/ 1 min. }\end{array}$ \\
\hline $\begin{array}{l}\text { PT/coligação Sim Por São Paulo com PSB, PC do B, } \\
\text { PMN, PCB/candidata Luiza Erundina/ 14min.18seg. }\end{array}$ & $\begin{array}{l}\text { PTB/ coligação São } \\
\text { Paulo Esperança com } \\
\text { PAN e PSD/candidato } \\
\text { José Campos } \\
\text { Machado/7min. }\end{array}$ \\
\hline $\begin{array}{l}\text { PDT/coligação Rossi por São Paulo com PL e } \\
\text { PST/candidato Francisco Rossi/ 8 min.45segs. }\end{array}$ & $\begin{array}{l}\text { PTN/coligação Bandeira } \\
\text { Paulista com PGT e PT } \\
\text { do B / candidato Dori- } \\
\text { val Masci de Abreu/ 1 } \\
\text { min.49 segs. }\end{array}$ \\
\hline Os partidos PPB, PMDB, PFL $e$ & $\begin{array}{l}\text { PRP/ candidato Carlos } \\
\text { Alves/ 1 min.49 segs. }\end{array}$ \\
\hline PSDC não realizaram
\end{tabular}
coligação para a eleição de vereadores (sistema proporcional) e o $P C O$ requereu apenas o registro de candidatos à vereador na Capital de São Paulo.

* A título ilustrativo, parece-nos oportuno, apontar algumas coligações e candidaturas registradas em outros municípios, capitais de Estados da Federação brasileira. Assim, no Rio de Janeiro, verifica-se a realização de 6 coligações: "Verde Arco Íris" (PPS, PV), "O Melhor Para o Rio" (PSDB, PMDB, $P L, P P B, P S D, P T B, P S C$ ) --só para a eleição majoritária, "Ptdo B-PGT (Ptdo B, $P G T)$ " "Rio Cidade Maravilhosa" (PST, PRP), "Unidade Popular" (PDT, PCdo B, $P S B) . \quad O$ PFL não integrou qualquer coligação, apresentando candidato isoladamente. Em Florianópolis, Estado de Santa Catarina, foram formadas 4 coligações: "Aliança Pela Vida" (PRTB, PAN, PMN, PSD, PV), "Força Capital" 
(PPB, PTB, PSDB), "Frente Popular" (PDT, PT, PCB, PPS, PSB, PC do B), "Nossa Cidade" (PFL, PL, PSC, PSL), O PMDB e o PSTU apresentaram candidatos independentemente de qualquer coligação. $O$ quadro de Porto Alegre, Estado de Rio Grande do Sul, oferece 4 coligações: "Frente Popular" (PT, PPS, PC do B), "União por Porto Alegre" (PSDB, PL, PFL, PSC, PSL), "União Social Popular" (PST, PMN, PSD, PRN), "Unidade Popular" (PC do B, PDT). Os partidos PTB, PPB, PSB, PSTU, PRONA, PMDB e PAN apresentaram candidaturas próprias, independentemente de qualquer coligação. Em Aracaju, Estado de Sergipe, há 7 coligações: "PDT/PTB", "PT/PCB/PCdoB", "PMDB/PSB", "PST/PRN" "PL/PPS/PFL": "PPB/PMN/PRP", "PTN/PSC/PTdo B" Os partidos PSTU, PSDC e PV apresentaram candidatos a prefeito sem coligação. Em Recife, Estado de Pernambuco, os partidos PPB, PT, PSTU, PSC, PFL, PPS, PSDB e PC do $B$ apresentaram isoladamente candidatos. Em Salvador, Estado da Bahia, há 5 coligações: "PDT/PSDB", "PT/PCB/PPS/PSB/PC do B" "PRN/PSD/PRP" "PTB/PSC/PL/PFL/PTdo B". Os partidos PMN, PGT, PMDB e PCO apresentaram individualmente candidaturas. Em Fortaleza, Estado do Ceará: os partidos PPB, $P D T, P M D B, P S L, P S C, P S N, P V, P S D B$ Pcdo $B$ e PT do $B$ apresentaram individualmente candidatos a prefeito. Em Belo Horizonte, Estado de Minas Gerais, há 7 coligações: "PSB/PMDB/PPS" "PSTU/PCO": "PRN/PST/PRP": "PT/PV/PCB/PCdo B", "PSDB/PL/PPB/PTB/PSL/PSD/PTdo B": "PDT/PMN/PAN/PRONA", "PFL/PSC". O partido PTN apresentou candidato isoladamente. Em Vitória, Estado de Espírito Santo, há 6 coligações: "PDSB/PDT/PV/PSDC", "PTB/PFL", "PMDB/PL/PCdo B", "PSB/PAN/PPS/PSN", "PSD/PST": "PMN/PSC" O PT, PPB, PDT e o PRN apresentaram candidaturas individuais. Em Curitiba Estado do Paraná: "PPB/PDT/PTB/PSC/PFL" "PT/PCB/PV/PC do B", PST/PL/PSDC/PT do B", "PSDB/PPS". Os partidos, PSB, $P M N, P T N, P S T U$ e PMDB apresentaram candidaturas isoladas. Em Belém, Estado do Pará, há 4 coligações, sendo que os partidos $P R N, P M D B, P P B$ e $P L$ apresentaram candidatos isoladamente. Em João Pessoa, Estado de Paraíba, há 4 coligações: "PPB/PDT/PC do $B$ " "PSC/PMN/PSD" "PSDC/PRN/PRP", "PSB/PSDB" Os partidos PCO, PSL e PSTU apresentaram candidatos isoladamente. Em Porto Velho, Estado de Rondônia, há 4 coligações: "PT/PCdoB/PV/PPS" "PSDC/PAN/PRP/PSN/PRN" "PDT/PPB/PL/PTB/PMN/PSD/PFL" "PMDB/PSDB". Os partidos PTdoB, PSB e PRONA apresentaram candidatos isoladamente. Em Boa Vista, Estado de Roraima, há 3 coligações: "PTB/PMDB/PP", "PDT/PL/PFL-PMN/PSB/PV/PSDB/PCdoB", "PT/PST/PTN/PSC/PPS/PSDC/PSD/PRP". Os partidos PRTB e PSL apresentaram candidatos isoladamente.

O exame do momento eleitoral, quando o enfoque se dirige ao partido político, impõe especial atenção à questão da responsabilidade das agremiações no que concerne ao espectro financeiro das campanhas e ao marketing político. 
Afastando-se da clássica responsabilização integral dos partidos pela propaganda e movimento financeiro das campanhas pré-eleitorais, o legislador (Lei n. 9.100, de 29.09.95) optou por atribuir solidariamente a partidos e candidatos, tal responsabilidade. Quanto à figura da agremiação, a esta foi acoplada, em caráter obrigatório, a tarefa de registrar comitê financeiro e a relativa à abertura de conta bancária específica para o registro de todo movimento financeiro, contemplando, de forma facultativa, os candidatos com essa última atribuição, com exceção dos candidatos a prefeito e, nos municípios com mais de 50 mil eleitores, também os aspirantes a mandato de vereador, para os quais impera também a obrigatoriedade, (art. $35, \S 3^{\circ}$ ). O preceito contido no $\S 5^{\circ}$ do já assinalado art. 35 é taxativo, porém, ao designar o candidato como

"o único responsável pela veracidade das informações financeiras e contábeis referentes à sua campanha..." embora persista a regra de que " $a$ prestação de contas à Justiça Eleitoral será sempre feita por intermédio do comitê financeiro e assinada pelo presidente do Partido." (art. $35, \S 7^{\circ}$ ).

Em verdade, o documento legal a disciplinar os pleitos de 1996 acompanha o espírito que norteou a produção da Lei n. 8.713/93 (eleições a nível federal e estadual de 1994), aprimorando, até, o tratamento oferecido naquela oportunidade a vários pontos de intensa e eterna nevralgia nos domínios das consultas eletivas. Continua paradoxal e nebulosa, porém, a definição da responsabilidade. O candidato é o único responsável? É ao partido, contudo, que foi cometido o dever da prestação final de contas à Justiça Eleitoral. E mais, em se tratando agora de pleitos municipais, vários serão os lugares a comportar campanhas a vereador realizadas por candidatos que não têm a obrigação e não abrirão conta bancária própria (art. $35, \S 3^{\circ}$ ). Nessa última hipótese, a campanha será desenvolvida pelo partido e alimentada financeiramente por contas partidárias. Ainda assim, persistirá a exclusividade pertinente à responsabilidade do candidato? 
4.- Do financiamento das campanhas

Cuida-se aqui do aspecto financeiro a envolver a operação eleitoral, tema de irrecusável notoriedade, porquanto ninguém há de ignorar que o custeio da atividade política demanda quantias cada vez mais vultosas, mormente nos momentos pré-eleitorais, ${ }^{5}$ quando a disputa pelo voto impõe a busca incontrolável de fontes de captação de receita, conduzindo invariavelmente a um processo periférico e nocivo de obtenção de aportes financeiros que desvirtuam e contaminam todo o cenário eleitoral.

A verdade é que a questão financeira a envolver a atividade partidária tem sido encarada com reserva, não-só por força das dependências que possam originar, como, também, em face do iminente perigo de deterioração da vontade popular expressa através do voto. Daí o vasto e grave repertório de escândalos, girando em torno do financiamento da atividade política, a ocupar os espaços da imprensa. Daí, ainda, a busca de meios e adequada regulamentação, aptos a intimidar, a desmotivar e a reduzir as práticas espúrias, timbradas pela corrupção. ${ }^{6}$

O legislador de 1995 (Lei n. 9.100) acompanhou, de perto, o espírito arrojado do texto normativo a comandar o pleito de 1994, editando normas mais consentâneas com as práticas de arrecadação de fundos, reconhecendo e regulamentando a captação de recursos no âmbito da esfera privada, de pessoas física e jurídica, de molde a assegurar um determinado equilíbrio à campanha (estabelecimento de limites art. 34), a transparência (visando identificar quem financia quem a obrigatoriedade do recibo previsto no $\S 5^{\circ}$ do art. 36 ), a lisura e a autenticidade da consulta.

Aprimorou o mecanismo pertinente à introdução de tetos máximos de contribuição e o respectivo controle, inaugurado por ocasião do pleito de 1994 ,

5. No artigo "Legalidade, Legitimidade e Corrupçāo em Campanhas Eleitorais", (v. Infra) de 1994, registrou a autora estudo elaborado pelo Professor Roberto Aguiar que apontava o elevado custo do voto no Brasil, cerca de $\$ 35.00$. Em recente levantamento promovido pela revista Veja (ed. de 31.07.96), verifica-se uma redução desse valor, sendo orçado o custo médio do voto para prefeito em $\$ 20.00$ e para vereador $\$ 10.00$. O montante de dinheiro que deve circular nas eleições municipais de 1996, na estimativa apresentada, implicará em cerca de 3 bilhões de dólares.

6. O fenômeno corrupção foi objeto de análise no artigo Legalidade, Legitimidade e Corrupção em Campanhas Eleitorais, da autora, in Cadernos Liberais, ed. Centro de Estudos Políticos e Sociais-CEPS, S.Paulo, Brasil. 
abandonando o sistema do "bônus eleitoral" para manter simplesmente a exigência do já aludido recibo a ser fornecido pelo candidato ou partido a cada contribuição, documento cuja confecção exige a lei formulário impresso em série própria para cada agremiação, segundo modelo aprovado pela Justiça Eleitoral. (art. 36, $\S 5^{\circ}$ )

Em resumo e para uma melhor visualização do quadro possível de doações em prol das campanhas eleitorais de partidos e candidatos, parece-nos oportuno registrar o seguinte esquema:

\section{*Limites de Doações}

\begin{tabular}{|c|c|}
\hline Pessoas Físicas & Pessoas Jurídicas \\
\hline $\begin{array}{l}10 \% \text { da renda de } 1995 \text { ou } 70 \text { mil UFIR (R\$ } \\
\left.61.929,00 \text { em } 1^{\circ} .07 .96\right) \text { - o que for maior }\end{array}$ & $\begin{array}{l}1 \% \text { da receita operacional bruta de } \\
1995 \text { ou } 300 \text { mil UFIR (R\$ } \\
\left.265.410,00 \text { em } 1^{\circ} .07 .96\right) \text { o que for } \\
\text { maior. }\end{array}$ \\
\hline $\begin{array}{l}\left.200 \text { UFIR (R\$176,94 em } 1^{\circ} .07 .96\right) \text {, quantia } \\
\text { não-sujeita à contabilização, que poderá ser } \\
\text { dispendida por qualquer cidadão em apoio } \\
\text { do candidato de sua preferência. }\end{array}$ & $\begin{array}{l}\text { Em relação a todos os candidatos de } \\
\text { determinada circunscrição } 2 \% \text { da } \\
\text { receita de impostos arrecadados pelo } \\
\text { Município em 1995, acrescida das } \\
\text { transferências constitucionais. }\end{array}$ \\
\hline
\end{tabular}

* Limites de Recursos do Próprio Candidato

$\rightarrow$ limite máximo estabelecido para despesas pelo partido ou coligação (art. $\left.36, \S 1^{\circ}, \mathrm{II}\right)$

*Vedações

$\rightarrow$ utilização de serviços gráficos custeados pelas Casas Legislativas, na hipótese de candidato detentor de mandato eletivo. (art. 40)

$\rightarrow$ doações de entidades estrangeiras, Administração Pública Direta e Indireta, concessionários e permissionários de serviço público, pessoas jurídicas ou físicas que mantenham contrato de obra ou serviço com o Poder Público, entidades declaradas de utilidade pública, entidades de classe ou sindical, pessoa jurídica, sem fins lucrativos, que receba recursos do exterior. (art. 37) 
$\rightarrow$ doações por intermédio de: confecção de material impresso de qualquer natureza; propaganda e publicidade, direta ou indireta, por qualquer meio; aluguel de locais para a promoção de atos de campanha; despesas com transporte ou deslocamento de pessoal a serviço das candidaturas; correspondência e despesas postais; instalação e funcionamento de comitês; montagem e operação de carros de som, de propaganda; confecção, aquisição e distribuição de camisetas, chaveiros e outros brindes; realização de pesquisas ou testes pré-eleitorais; aluguel de bens particulares para veiculação de propaganda eleitoral (art. 38) - tudo isto quando sua verificação ocorrer sem o registro da contribuição na forma regulamentar e se afigurar de valor superior a 200 UFIR.

\section{* Requisitos Formais}

$\rightarrow 0$ recibo, na forma preconizada no $\S 5^{\circ}$ do art. 36 ; excetuada a hipótese autorizada por força do art. 39;

$\rightarrow$ prestação de contas, na forma dos arts. 41 e seguintes.

$\rightarrow$ balancetes mensais ( $\S 3^{\circ}$ do art. 32 Lei n. 9.096/95)

\section{*Instrumentos de Arrecadação}

O dilema atinente ao levantamento de fundos de campanha, que os americanos reduzem à clássica expressão raising the money, impõe a utilização de modernas técnicas promocionais direcionadas, ao lado do fundo partidário ${ }^{7} \mathrm{e}$ das doações, a incrementar as possibilidades arrecadatórias, tema amplamente discutido no "Finanças Partidárias" publicado em $1983^{8}$ e que, a título ilustrativo, aponta, dentre outras, as modalidades infra-arroladas:

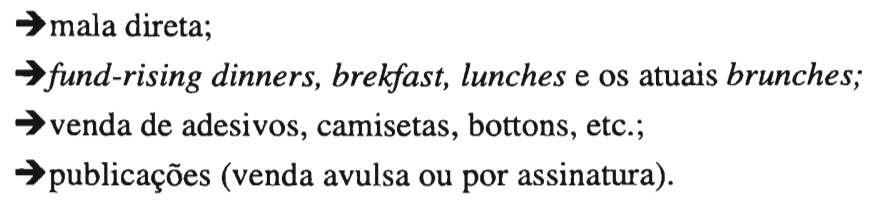

7. Segundo noticiado pelos jornais $O$ Estado de S. Paulo e Jornal da Tarde (ed. de 23.07.96), os partidos serão contemplados com cerca de $\mathrm{R} \$ 33$ milhões, o maior repasse já realizado pelo Tesouro Nacional, montante a ser repartido entre todos os partidos, sendo os maiores privilegiados os que contam com bancadas mais numerosas junto à Câmara dos Deputados. Noticia-se, ainda, projeto de lei em tramitação, aumentando ainda mais a verba destinada ao Fundo Partidário, sendo proposto um valor aproximado de $\mathrm{R} \$ 500$ milhões para partilha entre as agremiações. 1983.

8. Finanças Partidárias, Monica Herman Salem Caggiano, Brasília, Sen.Federal-Centro Gráfico, 
5.- Da propaganda eleitoral

A temática pertinente à veiculação publicitária vem disciplinada pelo diploma que comanda o pleito de 1996 em capítulo à parte (arts. 50 e seguintes), texto complementado pela Instrução n. 11, editada pela Superior Corte Eleitoral, quadro normativo norteado pelo princípio alojado no art. 237 do Código Eleitoral (Lei n. 4.737/65).

Em princípio, o legislador manteve o tratamento clássico, acompanhando de perto a linha adotada por ocasião das duas últimas consultas eletivas, de tom mais aberto e benevolente. Alguns itens impõem, contudo, uma atenção especial, em razão da eterna polêmica que suscitam. Dedicaremos, pois, maior atenção às modalidades permitidas, às vedações e a algumas hipóteses de maior teor nevrálgico.

\section{* Modalidades Permitidas}

Após a escolha em convenção, ${ }^{9}$ a partidos e candidatos é permitida a realização de propaganda, frisando o legislador a inviabilidade de cerceamento do marketing político-eleitoral por força de legislação municipal ou estadual.

Os veículos de divulgação albergam:

$\rightarrow$ fixação de faixas, placas, cartazes, pinturas, inscrições ou murais de qualquer dimensão em bens particulares,

$\rightarrow$ alto-falantes e amplificadores de voz, das 14 às 22 horas, instalados nas suas sedes e em veículos de partidos, candidatos ou coligações, sempre a pelo menos 200 m de distância das sedes dos Poderes e estabelecimentos enumerados no parágrafo único do art. 244 do Código Eleitoral, a exemplo de hospitais, bibliotecas, igrejas, teatros ou quartéis. (art. 53, $\S 4^{\circ}$, Lei n. 9.100/95),

$\rightarrow$ distribuição de folhetos, volantes e outros impressos (panfletagem) em vias e logradouros públicos;

\$aradoxal e inconstitucional nos parece, porém, a liberação ampla e global da panfletagem eleitoral, ignorando-se a legislação municipal, notadamente quando esta tem por escopo preservar a higiene e a estética urbana. A questão já foi suscitada perante o Poder Judiciário, advindo o entendimento de

9. $\mathrm{O} \S 1^{\circ}$, do art. 50 da lei eleitoral em vigor para o pleito de 1996 autoriza aos postulantes a legenda para candidatura a cargo eletivo promoverem suas campanhas uma semana antes da realização da convenção partidária. 
que "O Código Eleitoral, prevê em seu art. 248 que Ininguém poderá impedir propaganda eleitorall ... e dispõe no artigo seguinte que lo direito de propaganda não importa restrição ao Poder de Polícia, quando este deva ser exercido em beneficio da ordem públical. Bastante claro também o art. 243 que relaciona casos em que não será tolerada propaganda, entre eles, quando houver prejuízo à higiene e à estética urbana, ou Icontravenha a postura municipais ou a outra qualquer restrição de direitol"(Ac. n. 93.954, DOE 4.11.86). E em outros municípios, a exemplo da cidade de São Paulo, deve haver legislação de limpeza pública que veda a panfletagem nas ruas e logradouros públicos; parece-nos, pois, que tal legislação local - com suas penalidades e sanções deve prevalecer sob pena de lesar a previsão constitucional de competência reservada e exclusiva do Município (C.F. a.30. I) no que tangenciar o interesse local. E mais, a panfletagem irrestrita, tal qual pretendida pelo legislador eleitoral (art. 52) imporia aos municípios um ônus financeiro demasiadamente pesado (limpeza dos logradouros públicos, desobstrução de bueiros e bocas de lobo, etc.), o que também seria absurdo. Daí o nosso entendimento de que a propaganda por via de panfletagem deve adequar-se às disposições dos textos legais editados no âmbito de cada município.

$\rightarrow$ realização de comícios em recinto aberto ou fechado, independentemente de licença da Polícia e no horário compreendido entre 8 e 24 horas. $\mathrm{O}$ art. $3^{\circ}$ da Lei n. 1.207, de 25 de outubro de 1950, comete à Secretaria Estadual da Segurança Pública a tarefa de fixar, ao começo de cada ano, as praças destinadas à realização de comícios e o art. 53, $\S 1^{\circ}$ da Lei n. 9.100/95 (repetindo regra anterior do art. 245 C.E.) exige apenas mera comunicação à autoridade policial com 24 horas de antecedência, no ensejo de se assegurar uma determinada ordem e tranqüilidade a tais atos de propaganda.

*é interessante notar que a recente lei editada no Município de São Paulo (Lei Municipal n. 12.153, de 29 de julho de 1996), que dispõe sobre a necessidade de prévio aviso às autoridades municipais de trânsito nas hipóteses de manifestações públicas na Av. Paulista, visando assegurar o regular fluxo de tráfego na região, vai produzir reflexos sobre os atos de propaganda política, nessa modalidade, na indicada área. Por mais uma vez, porém, parece-nos oportuno assinalar a impositiva exigência de preservar o Poder de Polícia da autoridade municipal, interpretando a lei eleitoral de forma a não-nulificá-lo, pois, isto seria absurdo. 
$\rightarrow$ a modalidade conhecida como outdoor, que inunda ruas e avenidas no momento pré-eleitoral e que devido a sua larga utilização demandou regulamentação especial. A esse instrumento é dedicado o art. 55 da Lei n. 9.100/95, adotando-se a técnica do sorteio para a distribuição dos locais entre os partidos e rígida fiscalização da Justiça Eleitoral. A distribuição dos locais para a afixação do outdoor entre os candidatos de cada partido é tratada como questão interna corporis de cada agremiação $\left(\S 7^{\circ}\right.$, art. 55).

$\rightarrow$ divulgação na imprensa escrita, publicidade paga e que atende ao preceito do art. 54 da Lei n. 9.100/95 que limita a um oitavo de página de jornalpadrão e a um quarto de página de revista ou tablóide a propaganda de partido, candidato ou coligação.

$\rightarrow o$ rádio e a televisão, sendo assegurado, aos partidos e às coligações, horário gratuito pelo período de 60 dias anterior à antevéspera do pleito, partilhado, principalmente, com base na representação partidária junto à Câmara dos Deputados, nos moldes já configurados às fls. 8 deste trabalho. Na televisão, os partidos, conjuntamente, foram contemplados com uma hora de propaganda e nesse segmento publicitário introduziu, também, o legislador, o esquema das inserções ou spots de 30 a 60 segundos, a serem veiculados ao longo da programação diária das emissoras, independentemente do horário reservado à propaganda eleitoral. No rádio, o tempo destinado à publicidade eleitoral partidária é de uma hora e meia. Houve também previsão de dias específicos para a veiculação da propaganda aos cargos dos Legislativos (segundas, terças e quartas) e dias restritos à campanha para prefeito (terças, quintas e sábados). Há vedação expressa, contudo, quanto à publicidade paga ou compra de horário nesses veículos, complementando a produção apresentada no horário gratuito.

$\rightarrow$ debates - já tradicional entre nós a previsão de debates entre os candidatos, por via de rádio ou televisão, inclusive emissoras de televisão que operem em VHF e UHF A Lei n. 9.100/95 (arts. 62 e 63) assegurou a todos os candidatos eleições majoritárias e proporcionais - a participação em debates. No que toca aos pleitos majoritários previu duas possibilidades: a primeira, com a presença de todos os candidatos e a segunda, em grupos, devendo, nesta última hipótese, a escolha do dia e da ordem de fala ser feita mediante sorteio, salvo se celebrado acordo diverso entre os candidatos. É de se observar, no entanto, que, já na realização do primeiro debate a envolver apenas um grupo de candidatos a prefeito no Município de São Paulo, a Justiça Eleitoral, por decisão datada de $1^{\circ}$ de 
julho de 1996 , do Juiz da $1^{\text {a }}$ Zona, garantiu a presença dos demais candidatos dos denominados partidos "nanicos".

No que concerne às candidaturas aos Legislativos Municipais (vereador), o documento preconizou, na organização dos debates, garantia da presença de, pelo menos, três partidos concorrentes. Deixou, porém, à livre escolha do partido a indicação de seus representantes no encontro, entendendo a questão, pois, como de interesse interna corporis.

$\rightarrow$ presença de autoridades faceta de elevado grau de nevralgia do momento eleitoral, até agora, a questão da participação das autoridades nas produções de marketing eleitoral ganhou tratamento mais ameno no cenário dos pleitos municipais de 1996. Por intermédio da regra do art. 61, o legislador assegurou a participação, em apoio aos candidatos, de qualquer cidadão filiado ou não ao partido daqueles, vedando apenas a presença remunerada e a propaganda que possa degradar ou ridicularizar candidatos, ainda que de forma dissimulada. E mais, nessa linha, previu para o segundo turno, onde o reagrupamento partidário é obrigatório, a participação de filiados a partido diferente daquele defendido pelo candidato que pretende apoiar.

A regra, da forma como idealizada pelo legislador, aberta e sem restrições, colidiu frontalmente com posicionamentos já consolidados no âmbito da Justiça Eleitoral, posturas mais restritivas que impediam o apoio claro e expresso das autoridades em prol de seus candidatos. Suscitada a temática perante o E. Tribunal Superior Eleitoral, houve inequívoca remodelação do entendimento anteriormente perfilhado, advindo a Resolução n. 19.608, de 11.06.96, que, alterando a redação do inciso IX do art. 58 da Instrução n. 11 (Res. n. 19.512, de 18.04.96), consagrou a presença das autoridades nos palanques e demais veículos publicitários ao dispor que a tais personalidades somente será vedado "participar de atos públicos de campanha eleitoral do candidato ou partido político, quando acarrete o comprometimento de recursos públicos". (DJU 21.06.96)

$\rightarrow$ propaganda em táxis - a matéria já foi objeto de abordagem, notadamente no tocante ao Município de São Paulo, por ocasião das eleições de $1990,{ }^{10}$ quando se demonstrou a excrescência do Decreto municipal n. 22.252, de 28 de maio de 1986. Isto, de um lado, porque não havia e continua incorrendo qualquer

10. "Eleições 90 e o seu Metabolismo", Monica Herman Salem Caggiano, in Cadernos Liberais 97-90, edição do Instituto Tancredo Neves de Estudos Políticos e Sociais, São Paulo, 1990. 
vedação expressa na lei eleitoral quanto à exploração de publicidade políticopartidária e a afixação de cartazes de candidatos a postos eletivos no interior de táxis e, de outro, porque a Lei municipal n. 9.387, de 21.12.81, autorizativa dessa espécie de propaganda, encarregou a autoridade regulamentadora (o Executivo) tão-só do delineamento das normas técnicas, tipo: dimensões, formato, área de exposição, etc. Não lhe oferece, todavia, qualquer brecha para introdução de impedimentos quanto à matéria a ser veiculada por esse sistema de marketing. Evidente, assim, a conotação de praeter legem da regulamentação proposta por força do indigitado decreto.

Reflexo imediato da revogação parcial do já assinalado Decreto $n$. 22.252/86, a manifestação do MM. Juiz da $1^{\text {a }}$ Zona Eleitoral do Município de São Paulo que, transformando uma representação de vereador do PT em consulta, resolveu respondê-la (proc. n. 028/96 $1^{\text {a }}$ Zona Eleitoral). Reconhecendo a inviabilidade de discutir o decreto revocatório municipal nessa sede, traçou, porém, orientação no sentido de que questionado ato de propaganda viria a ser proibido por força da regra do art. 51 da Lei n. 9.100/95.

Ora, é de se notar que assinalado preceito, como aliás é frisado nessa r. decisão, impede propaganda em "bens cujo uso dependa de cessão, permissão ou concessão do Poder Público"; o serviço de táxi não se enquadra em qualquer dessas hipóteses legais. É um bem particular que detém mera licença para operar no âmbito do transporte individual de passageiros. E não há como ignorar que as disposições legais restritivas, uma característica indissociável da norma eleitoral, devem ser interpretadas de forma estrita, restando vedado qualquer exercício de hermenêutica de maior elasticidade. Em especial, a produção e o exercício da propaganda eleitoral, meio de divulgação e veiculação dos personagens que postulam cargos eletivos, não pode sofrer processos de engradamento e intimidação, totalmente destoantes da perspectiva participativa própria do período pré-eleitoral. Este, em verdade, pressupõe uma exacerbação do exercício do direito, constitucionalmente consagrado e tutelado, de livre e ampla manifestação e exteriorização do pensamento tudo em homenagem e atendimento do cânone democrático conhecido como free and fair elections. ${ }^{11}$

11. O problema a envolver a questão publicitária em terreno eleitoral toca de perto a discussão pertinente à liberdade de manifestação do pensamento tanto em relação ao eleitor quanto do prisma do candidato. $\mathrm{O}$ tema foi objeto de amplo debate no cenário norte-americano logo após a revisão legal procedida em 1974 e que introduziu um esquema mais rígido de controle sobre o aprovisionamento das atividades partidárias. Memorável a decisão proferida pela Suprema Corte dos Estados Unidos, no caso "Buckley X Valeo" (30.07.76), eliminando grande parte dessas restrições sob a argumentação de 
Fato é que não há na legislação em vigor qualquer regra expressa inibidora dessa espécie publicitária, o que, a nosso ver, impõe a revisão do posicionamento adotado em primeiro grau por parte da Justiça Eleitoral.

$\rightarrow$ circuito fechado de som e imagem a que o público tenha acesso $e$ vídeos desde que a publicidade produzida (em salas de cinema ou espetáculos teatrais ou, ainda, por via de vídeos locados) venha a ser paga e devidamente contabilizada pelo partido, coligação ou candidato, não há qualquer óbice legal à veiculação.

\section{*Vedações}

$\rightarrow$ material publicitário produzido pelos serviços gráficos das Casas Legislativas, beneficiando candidato detentor de mandato parlamentar (art. 40, Lei n. 9.100/95).

$\rightarrow$ propaganda em bens cujo uso dependa de cessão, permissão ou concessão do Poder Público ou em bens públicos, englobando tal proibição as pichações, as inscrições, afixação de cartazes ou qualquer outra veiculação publicitária.

$\rightarrow$ a partir de $1^{\circ} .07 .96$ a veiculação, por emissoras e ainda que no curso de sua programação normal, de entrevistas jornalísticas com candidatos, de pesquisas ou consultas de natureza eleitoral em que seja possível a manipulação de dados; a utilização de trucagem, montagem ou outro recurso de vídeo ou áudio de forma a ridicularizar ou degradar partido, candidato ou coligação; difundir opinião favorável ou contrária a partido, candidato ou coligação; oferecer tratamento privilegiado a candidatos, partidos ou coligações; quaisquer alusões, na sua programação cotidiana - novelas, minisséries, etc. a partido, candidato ou coligação (art. 64, Lei n. 9.100/95).

$\rightarrow a$ partir de 02.08 .96 transmitir programa apresentado ou comentado por candidato ou divulgar nome de programa, ainda que preexistente, se coincidente com variação nominal adotada por candidato (art. $64, \S 3^{\circ}$ ).

que tal linha vedativa implicava uma ofensa à Emenda n. 1 do Estatuto Fundamental, por conduzir a restrições quanto à liberdade de expressão, posto que importaria em limitações quanto à profundidade dos debates, temas a serem debatidos e em limitação quanto à amplitude da audiência a ser alcançada . (in "Electing Congress", abril de 1978, p. 110) 
$\rightarrow$ qualquer ato de propaganda, de valor superior a 200 UFIR e que não tenha sido objeto de correta contabilização por parte do partido ou candidato (art. 38 CC art. 39 - Lei n. 9.100/95).

\section{*Pesquisas Eleitorais}

Clássica a postura refratária do legislador no que concerne à divulgação de prévias ou pesquisas eleitorais, sempre encarando esse meio informativo como de alto risco para a lisura e sinceridade do resultado eleitoral, por rotulá-lo como de elevado potencial de ingerência na exteriorização da vontade política do eleitor. Já em 1987 (Sistemas Eleitorais e Representação Política), ${ }^{12}$ contudo, demonstramos a reduzida capacidade de aliciamento eleitoral desse instrumento, refletindo sua proibição um significativo prejuízo e, até mesmo, infringência ao direito de informação a todo assegurado.

O texto normativo a comandar o pleito de 1996 contemplou o segmento com um tratamento mais adequado, afastando-se da linha vedativa para autorizar sua produção; porém, sob rígido sistema de controle. Ao tema, a lei atual dedica capítulo à parte, arts. 48 e 49, dispositivos que, por intermédio de seus múltiplos incisos e parágrafos, oferecem à matéria uma regulamentação que visa impedir a manipulação de dados e a transmissão de informações tendenciosas ao eleitorado.

Começa a lei por introduzir um termo inicial de incidência, 02.04.96, data a partir da qual quaisquer pesquisas de opinião pública relativas às eleições ou aos candidatos passam a se subordinar à regência de um sistema de controle norteado pelos princípios da informação - quem contratou a pesquisa, valor e origem dos recursos financeiros, metodologia, margem de erro, etc. - e da ciência e possibilidade de impugnação pelos interessados. A vedação persiste, nos novos moldes, tão-só, em relação às pesquisas não-registradas junto à Justiça Eleitoral, que, portanto, deixaram de atender ao procedimento de fiscalização imposto e em relação às denominadas sondagens de "boca de urna". Estas últimas inviabilizadas em razão da impossibilidade do atendimento do prazo de carência registro junto à Justiça Eleitoral cinco dias antes da sua divulgação.

12. Monica Herman Salem Caggiano, Sistemas Eleitorais X Representação Política, Brasilia, Senado Federal, 1990. 
6.- Do direito de resposta

Segmento eleitoral sobre o qual o legislador vem se debruçando de forma particular, introduzindo tópicos de flagrante aprimoramento, o quadro atinente ao direito de resposta foi merecedor de tratamento específico no âmbito do documento legal editado em 1995, (art. 66, com seus 12 parágrafos, sendo os três primeiros integrados por um expressivo rol de incisos), denotando uma acentuada preocupação com o delineamento de um procedimento célere e eficaz a coibir ou, ao menos, apto a corrigir e remediar situações que se afigurem ofensivas a candidatos, partidos, coligações, por via da transmissão de imagens ou afirmações caluniosas, difamatórias, injuriosas ou sabidamente inverídicas.

Nessa perspectiva, é de se notar, inicialmente, que o texto cuidou em separado das hipóteses de ofensa por intermédio da imprensa escrita, por via audiovisual (rádio e televisão), programação normal e horário gratuito. E mais, estabeleceu exíguos prazos para as partes, como também para o próprio Juiz, robustecendo, inclusive, as partes, por contemplá-las com a faculdade de, em não sendo proferida a decisão nos prazos fixados, se dirigirem aos órgãos superiores da Justiça Eleitoral, na busca do provimento jurisdicional (art. 66, §12 CC com art. $65, \S 6^{\circ}$ ). E mais, ainda, puniu o não-cumprimento da ordem com sanção pecuniária ( 11 , art. 66), a par de reforçar sua tipificação como crime eleitoral, ao qual é acoplada a pena de detenção de 3 meses a 1 ano. (art. 347, C.E.)

Demais disso, preconizou determinadas condições - de forma e de fundo para o exercício dessa prerrogativa, acoplando-lhe um procedimento rápido, preordenado ao atingimento concreto da finalidade do próprio instituto.

\section{*Ofensa praticada pela imprensa escrita:}

$\rightarrow$ condições de fundo:

$\Rightarrow$ legitimidade (competência) -

partido, candidato ou coligação.

\$ embora o diploma legal mencione como titulares do direito de resposta apenas partidos, candidatos ou coligações (elenco ao qual a Resolução editada pelo TSE acrescentou também a figura do eleitor), parece-nos evidente que tal prerrogativa se estende a todo e qualquer ente que venha a ser alvo da ofensa de cunho eleitoral, restando a esse, também, facultado o procedimento previsto 
para o reparo moral, finalidade precípua desse instituto. Este entendimento decorre, de forma natural, até, do próprio preceito assecuratório consagrado no art. $5^{o}, V$ da Constituição Federal (direito de resposta), reafirmado em sede eleitoral por força do respectivo Código (Lei n. 4.737/65), no art. $243, \S 3^{\circ}$.

$\Longrightarrow$ hipóteses admissíveis:

calúnia, difamação, injúria ou afirmação sabidamente inverídica.

\section{$\rightarrow$ condições de forma:}

$\Rightarrow$ instrução do pedido: exemplar da publicação e o texto da resposta.

$\Rightarrow$ prazo de defesa: 48 horas

$\Rightarrow$ prazo global para a instrução e julgamento: três dias contados da data da formulação do pedido.

$\Rightarrow$ ônus da prova relativa à adequada veiculação da resposta: ofensor.

$\Rightarrow$ prazo de recurso: 48 horas da publicação, previsto igual prazo para o oferecimento de contra-razões.

* Ofensa praticada por intermédio de emissoras de rádio e televisão/programação normal

$\rightarrow$ condições de fundo: idênticas à hipótese anterior.

$\rightarrow$ condições de forma:

$\Rightarrow$ instrução do pedido: não há necessidade da exibição do material ofensivo. A Justiça Eleitoral notificará o responsável pela emissora para que entregue em 24 horas cópia da fita da transmissão.

$\Rightarrow$ prazo de defesa: não há; presume-se que eventual defesa deverá ser produzida juntamente com a apresentação do material de prova requisitado.

$\Rightarrow$ prazo global para instrução e julgamento: 72 horas.

$\Rightarrow$ prazo de recurso: 48 horas tratamento idêntico à hipótese anterior.

* Ofensa praticada por intermédio de emissoras de rádio e televisãol horário gratuito.

$\rightarrow$ condições de fundo: idênticas.

$\rightarrow$ condições de forma:

$\Rightarrow$ apresentação do pedido: 24 horas do término da transmissão. 
$\Rightarrow$ instrução do pedido: não há necessidade de exibição do material ofensivo.

$\Rightarrow$ prazo para notificação do ofensor para a defesa: 24 horas.

$\Rightarrow$ prazo para a defesa: 24 horas.

$\Rightarrow$ prazo global para a instrução e julgamento: 72 horas.

$\Rightarrow$ tempo de resposta: nunca inferior a um minuto.

$\Rightarrow$ prazo de recurso: 48 horas.

\section{7.- Das representações e reclamações}

A par do direito de resposta e no mesmo sentido de preservação da moralidade, da ética e do espírito cívico que devem emoldurar o momento préeleitoral, o legislador disciplinou a via das representações e das reclamações denunciadoras do não-cumprimento da legislação e causas de eventual ruptura do equilíbrio de atuação que deve ser assegurado a todas as facções que ingressam na corrida pelo voto.

Nesse sentido a abrangente regra do art. 65 da Lei n. 9.100/95, que, em moldes similares aos prescritos no que toca ao direito de resposta, vem delinear um procedimento célere, fixando os seguintes requisitos:

\section{$\rightarrow$ condições de fundo:}

$\Rightarrow$ legitimidade (competência): qualquer eleitor, candidato, partido, fiscal, delegado.

$\Rightarrow$ hipótese de admissão: denúncia de irregularidade nos quadros da publicidade eleitoral ou qualquer outra atuação que venha a lesar os dispositivos da legislação de regência das eleições de 1996.

\section{$\rightarrow$ condições de forma:}

$\Rightarrow$ apresentação da reclamação ou representação, afigurando-se oportuna e recomendável a adequada instrução do documento; não é contudo impositivo o oferecimento de provas.

$\Rightarrow$ notificação imediata do reclamado

\$em sendo candidato, a notificação poderá ser feita ao partido ou coligação a que pertença. 
$\Rightarrow$ prazo para defesa: 24 horas.

$\Rightarrow$ prazo global para decisão: 72 horas.

$\Rightarrow$ prazo para recurso: 24 horas, sendo autorizadas contra-razões em igual prazo.

$\Rightarrow$ prazo para julgamento em segundo grau: 24 horas.

* na hipótese de inobservância dos prazos por parte da Justiça

Eleitoral, faculta-se às partes conduzirem a questão à apreciação dos Tribunais Superiores. $\left(\S 6^{\circ}\right.$, art. 65$)$

8.- Do dia da eleição

Por tradição e considerando que o eleitor necessita de algumas horas de reflexão para a emissão de um voto consciente, bem como em homenagem à garantia da livre expressão das preferências políticas, a lei eleitoral veda "desde quarenta e oito horas antes até vinte e quatro horas depois da eleição, qualquer propaganda política mediante radiodifusão, televisão, comícios ou reuniões públicas" (parágrafo único, art. 240 C.E.). A par disso, à semelhança da legislação alienígena (exemplo francês e norte-americano), que dedica especial tratamento ao dia das eleições, por intermédio de legislação especial, editada a cada pleito, tem procurado definir normas que assegurem e complementem a eficácia desse princípio, erigindo o desatendimento a figuras penais, além das cominações de ordem pecuniária que são impostas. Em regra, busca-se o atingimento e a eficácia das garantias eleitorais, direcionadas a viabilizar a autêntica, livre e soberana manifestação da vontade por parte de cada um dos eleitores, isto por intermédio de precauções com a identificação do votante, com o seu isolamento, a proteção da cédula e a urna.

O texto legal elaborado para regulamentar o quadro eleitoral de 1996 não se afastou dessa regra. Foi mais rígido até, impedindo em quaisquer lugares e não apenas nas proximidades das seções eleitorais - a distribuição de volantes e outros impressos, o funcionamento de postos de distribuição de material publicitário e outros atos de propaganda. Contemplou, ainda, vedação expressa a "qualquer forma de aliciamento ou coação tendente a influir na vontade do eleitor". E mais, tipificou o não-cumprimento dessas determinações como crime eleitoral, acoplando 
à primeira dessas hipóteses sanção pecuniária (multa) e à segunda a pena de detenção de 1 a 3 meses. (art. 67, IX e X)

Atenuando os efeitos da drástica restrição contida no inciso IX, art. 67, da lei, a Instrução de n. 11 (Propaganda) baixada pelo E. Tribunal Superior Eleitoral explicitou que resta vedado, durante o dia da votação, "em qualquer local público ou aberto ao público, a aglomeração de pessoas, portando os instrumentos de propaganda (inscrições no vestuário, bandeiras, flâmulas ou adesivos em veículos), de modo a caracterizar manifestação coletiva ...". Autorizou, porém, "a manifestação individual e silenciosa da preferência do cidadão por partido, coligação ou candidato, ...". utilizando tais meios. (art. 57, caput e $\S 1^{\circ}$ ). Evidenciou, ademais, que os fiscais, no decurso da votação, poderão portar nas suas vestes o nome ou a sigla do respectivo partido ou coligação. (art. $57, \S 3^{\circ}$ )

O dia da eleição, como já assinalado, engloba outras garantias, a par das atinentes à questão publicitária, tudo no sentido de prestigiar o cânone maior, insculpido no art. 234 do Código Eleitoral que dispõe: "ninguém poderá impedir ou embaraçar o exercício do sufrágio". Nesse diapasão, a regra inibidora da prisão ou detenção de eleitor, salvo em flagrante delito ou em virtude de sentença criminal condenatória por crime inafiançável, ou ainda, por desrespeito a salvo-conduto isto desde cinco dias antes e até 48 horas depois do encerramento da eleição. (art. 236, caput - C.E.) Nessa linha, também, o impedimento quanto à prisão dos membros das Mesas-Receptoras e dos fiscais dos partidos ou coligações, no exercício de suas funções. (art. $236, \S 2^{\circ}$ C.E.) $\mathrm{E}$, ainda, nesse sentido, a proibição relativa à presença de força pública no edifício em que funcionar Mesa-Receptora ou nas imediações. Aliás, como garantia da liberdade do voto, no período compreendido entre as 72 horas que antecederem a realização do pleito e as 48 horas imediatamente posteriores, desloca-se o poder policial para a autoridade eleitoral (art. 235, C.E.).

Ressuscitando precaução abandonada pela Justiça Eleitoral, de identificar o eleitor por fotografia, porquanto há tempos já o título de eleitor não traz esse dado, ${ }^{13}$ a lei atual impôs, por via do seu art. 75 , a apresentação conjunta do respectivo título e de um documento oficial do qual conste a fotografia daquele, introduzindo sérios óbices à exteriorização da vontade política pelo voto. Isto porque uma grande maioria dos eleitores dos municípios do interior não possuem esse

13. A Lei n. $7.444 / 85$, art. $5^{\circ}, \S 4^{\circ}, \mathrm{CC}$ com art. $1^{\circ} \S$ único, dispensa de fotografias no processamento eletrônico do alistamento. 
documento, para muitos afigurando-se suficiente o título eleitoral para o exercício da cidadania. Dúvidas não restam de que a exigência suplementar do texto regulamentador incidente sobre os pleitos de 1996 afigura-se meritória, decorrente da preocupação a cercar a correta identificação do eleitor; afigura-se, porém, inconstitucional por exigir dupla identificação para o exercício do direito de sufrágio, limitando-o e ignorando o único requisito insculpido no Estatuto Fundamental, ou seja o alistamento. E este é comprovado tão-só pela apresentação do título de eleitor; exigir mais significa um retrocesso, podendo-se, nessa trilha, chegar até ao sufrágio censitário, o que seria absurdo.

Outro tópico a demandar especial enfoque é o relativo à atuação dos fiscais e delegados dos partidos, em plena atividade no dia da eleição. Cada partido ou coligação poderá nomear dois delegados em cada município naqueles que contem com mais de uma Zona Eleitoral, dois delegados junto a cada uma delas e dois fiscais junto a cada Mesa-Receptora, sendo que estes atuarão um de cada vez. O credenciamento dessas figuras é atribuição das agremiações ou coligações, exigindo-se apenas a indicação, aos Juízes Eleitorais, do nome das pessoas autorizadas a expedir a credenciais dos fiscais e dos delegados.

Compete aos fiscais e delegados, conjuntamente com os candidatos, fiscalizar a votação e a apuração, formular protestos e fazer impugnações, inclusive sobre a identidade do eleitor, vigiar e fiscalizar a urna, bem como todo o material referente à eleição. Aliás, acentuada é a responsabilidade desses personagens, na medida em que, em sede eleitoral, salvo raras exceções, a ausência de impugnação no momento oportuno, torna a matéria preclusa, inviabilizada restando a via judicial para a discussão da eventual irregularidade.

\section{9.- Da apuração/ Da validade do voto}

Cuida-se aqui do momento de contagem dos votos, matéria objeto de remodelação legal em 1990, quando se optou por uma linha de privilegiamento do candidato, em detrimento do partido, reforçando-se a postura de priorização do nome do candidato como indicativo da expressão da vontade eleitoral e desprezando-se a indicação por número. No âmbito do processo convencional de votação - não eletrônico há regras claras a distinguir os votos nulos, i.é. aqueles que não estampam qualquer exteriorização da vontade eleitoral (são absolutamente vazios, sem conteúdo) daqueles que, embora defeituosos, oferecem possibilidades 
de apreensão da efetiva e verdadeira preferência eleitoral por seu intermédio expressada. Assim, alguns equívocos acabaram sendo perdoados, desde que decifrável a opção eleitoral, com respaldo nas regras interpretativas dos arts. 176 e 177 do Código (Lei n. 4.737/65).

Dúvidas, no entanto, emergem quanto ao tratamento da vontade eleitoral no âmbito do novo sistema eletrônico de votação e apuração. Neste caso será a própria máquina, de acordo com alimentação padronizada, a decidir se este ou aquele voto poderá ser considerado válido. O eleitor estará trabalhando com números - e muitos nos pleitos proporcionais, para vereador -, o nome não mais terá o peso que tem na votação e apuração pela técnica tradicional.

O processo eletrônico constitui, não há dúvida, um avanço; uma conformização aos tempos contemporâneos dominados pela informática, da qual, parece-me, não há como se esconder. Evidente, contudo, que a máquina não poderá expressar com a mesma fidelidade a vontade do eleitor, será incapaz de qualquer esforço interpretativo da opção eleitoral; e mais que isso será incapaz de espelhar resultados de protesto, a exemplo do "voto cacareco" que integra o nosso folclore eleitoral. 
De forma geral, contudo, poderíamos nos permitir elaborar o seguinte quadro esquemático, ilustrativo das hipótese de validade ou invalidade do voto:

\section{\begin{tabular}{l|l} 
Eleições Majoritárias & Eleições Proporcionais
\end{tabular}}

\begin{tabular}{|c|c|c|c|c|}
\hline Voto Nulo & Voto Válido & Voto Nulo & $\begin{array}{l}\text { Voto Válido } \\
\text { p/a Legenda }\end{array}$ & \begin{tabular}{|l|} 
Voto válido $\mathrm{p} /$ \\
$\mathrm{o}$ candidato \\
\end{tabular} \\
\hline $\begin{array}{l}\text { Voto em } \\
\text { branco. Voto } \\
\text { conferido em } \\
\text { cédula não- } \\
\text { oficial, em } \\
\text { cédula não- } \\
\text { autenticada, } \\
\text { ou que } \\
\text { contiver ex- } \\
\text { pressões ou } \\
\text { símbolos que } \\
\text { possam iden- } \\
\text { tificar o voto. }\end{array}$ & $\begin{array}{l}\text { Voto que iden- } \\
\text { tifique a vontade } \\
\text { política do elei- } \\
\text { tor. O voto que } \\
\text { indicar apenas a } \\
\text { sigla partidária, o } \\
\text { número de } \\
\text { registro ou, ain- } \\
\text { da, expresso na } \\
\text { parte da cédula } \\
\text { destinada à elei- } \\
\text { ção proporcional. }\end{array}$ & $\begin{array}{l}\text { Voto confe- } \\
\text { rido em cé- } \\
\text { dula não- } \\
\text { oficial, ou } \\
\text { fora do pro- } \\
\text { cedimento } \\
\text { adotado. }\end{array}$ & $\begin{array}{l}\text { Voto em bran- } \\
\text { co. Voto que } \\
\text { registrar a si- } \\
\text { gla partidária; } \\
\text { que registrar } \\
\text { dois ou mais } \\
\text { candidatos do } \\
\text { mesmo par- } \\
\text { tido; que não } \\
\text { indique o can- } \\
\text { didato com } \\
\text { clareza neces- } \\
\text { sária para } \\
\text { distinguí-lo de } \\
\text { outro do mes- } \\
\text { mo partido. }\end{array}$ & $\begin{array}{l}\text { Voto que } \\
\text { registre o nome } \\
\text { de um candi- } \\
\text { dato e o núme- } \\
\text { ro de outro; } \\
\text { que indique no- } \\
\text { me de candi- } \\
\text { dato ou seu } \\
\text { número e a } \\
\text { sigla de outro } \\
\text { partido. }\end{array}$ \\
\hline
\end{tabular}

*O voto em branco é considerado válido e aproveitado nos pleitos proporcionais. É computado para a fixação do quociente eleitoral e acaba beneficiando, na distribuição das cadeiras, o partido de maior densidade eleitoral no momento, i.é., aquele que consegue o maior número de assentos.

São Paulo, julho de 1996. 